\title{
Screening and Application of Bacillus Strains Isolated from Nonrhizospheric Rice Soil for the Biocontrol of Rice Blast
}

\author{
Yuexia Sha (iD ${ }^{1 *}$, Qingchao Zeng ${ }^{2}$, and Shuting Sui ${ }^{2}$ \\ ${ }^{1}$ Institute of Plant Protection, Ningxia Academy of Agriculture and Forestry Sciences, Yinchuan 750011, China \\ ${ }^{2}$ College of Plant Protection, China Agricultural University, Beijing 100193, China
}

(Received on February 9, 2020; Revised on April 1, 2020; Accepted on April 27, 2020)

Rice blast, caused by Magnaporthe oryzae, is one of the most destructive rice diseases worldwide. The aim of this study was to screen bacterial isolates to efficiently prevent the occurrence of rice blast. A total of 232 bacterial isolates were extracted from nonrhizospheric rice soil and were screened for antifungal activity against $M$. oryzae using a leaf segment assay. Strains S170 and S9 showed significant antagonistic activity against $M$. oryzae in vitro and in leaf disk assays, and controlled $M$. oryzae infection under greenhouse conditions. The results showed that strains $\mathbf{S 1 7 0}$ and S9 could effectively control rice leaf blast and panicle neck blast after five spray treatments in field. This suggested that the bacterial strains $\mathbf{S 1 7 0}$ and $\mathbf{S 9}$ were valuable and promising for the biocontrol of rice disease caused by M. oryzae. Based on 16S rDNA, and gyrA and gyrB gene sequence analyses, S170 and S9 were identified as Bacillus amyloliquefaciens and $B$. pumilus, respectively. The research also demonstrated that $B$. amyloliquefaciens S170 and $B$. pumilus $\mathbf{S 9}$ could colonize rice plants to prevent pathogenic infection and evidently suppressed plant disease caused by 11 other plant pathogenic fungi. This is the first study to demonstrate that B. amyloliquefaciens and $B$. pumilus isolated from nonrhizospheric rice soil are capable of recolonizing internal rice stem tissues.

\footnotetext{
*Corresponding author.

Phone) +86-951-6886807, FAX) +86-951-6886917

E-mail)yuexiasha@126.com

ORCID

Yuexia Sha

https://orcid.org/0000-0002-2426-8218

(cc) This is an Open Access article distributed under the terms of the Creative Commons Attribution Non-Commercial License (http:// creativecommons.org/licenses/by-nc/4.0) which permits unrestricted noncommercial use, distribution, and reproduction in any medium, provided the original work is properly cited.
}

Articles can be freely viewed online at www.ppjonline.org.
Keywords : Bacillus, biocontrol, nonrhizospheric rice soil, rice blast, screening

Handling Editor : Yong Hoon Lee

Rice is the most important grain crop and provides the main food energy for more than $50 \%$ of the world population every day (Food and Agriculture Organization of the United Nations, 2012). Rice blast, a widespread and destructive disease caused by Magnaporthe oryzae B. Couch (Pyricularia grisea [Cooke] Sacc.), has occurred in more than 85 countries worldwide and causes $30 \%$ of annual rice yield losses, which could feed 60 million people (Dagdas et al., 2012; Muthayya et al., 2014). M. oryzae can infect every tissue of rice plants, causing blast leaf and panicle neck blast, which significantly damage grain yield and quality. At present, breeding disease-resistant varieties and applying chemical pesticides are the main strategies used to control rice blast disease. Breeding new varieties takes a long time, during which the physiological race of $M$. oryzae can easily change. Moreover, chemical fungicides often cause fungicide resistance, residual toxicity and threaten to food safety. Therefore, a safe and environmentally friendly strategy for the biological control of rice blast is urgently required.

It is well known that soil bacteria can reduce the severity of disease caused by fungal pathogens and promote plant growth (He et al., 2019). Various soil bacteria such as Bacillus spp., Pseudomonas spp., and Actinomycetes spp. have been assessed for their capacity to biocontrol rice blast in the field (Chaiharn et al., 2009; Jambhulkar et al., 2018; Rais et al., 2016; Wu et al., 2018), inhibit the growth of $M$. oryzae mycelia and suppress diseases in vitro (Amruta et al., 2016; Kumar et al., 2017). Bacillus spp. belong to the phylum Firmicutes and produce spores. They are character- 
ized by an ability to biocontrol many diseases and pests, promote plant growth, yield and stress resistance, and improve the soil nutrient condition. In addition, Bacillus spp. have many ecological functions including acting as microbial fertilizers, restoring contaminated soil, and degrading cellulose, and are applied extensively for sustainable agricultural development.

Bacillus spp. colonize rice plants and compete with plant pathogens for colonization sites and nutrients. These species also produce antimicrobial metabolites that inhibit the growth of pathogen hyphae and conidia. Furthermore, Bacillus spp. dissolve pathogenic cell walls using different enzymes to reduce disease severity. Bacillus spp. also stimulate induced systemic resistance to promote plant resistance to disease and abiotic stress. Therefore, an increasing amount of research has focused on screening Bacillus spp. to obtain biological control agents. The fermentation broth or culture filtrate of B. subtilis strain BJ-1 was found to completely suppress the growth of $M$. oryzae on detached leaves and when applied as seed treatment against rice blast (He et al., 2019). Several Bacillus spp. isolated from rice leaves by Wiraswati et al. (2019) were found to inhibit the growth of $M$. oryzae using polyketide synthase and nonribosomal peptide synthetase genes. B. subtilis BS155 can suppress the growth of $M$. oryzae via the production of cyclic lipopeptides named fengycin BS155 (Zhang and Sun, 2018).

Bacillus strains reported in previous studies have mainly been isolated from the rhizosphere zone (Amruta et al., 2016), with few strains coming from the nonrhizospheric rice soil (soil cores without rice plants). Moreover, many reports have focused on the antifungal activity and metabolites of Bacillus. Rais et al. (2016) screened five Bacillus spp. isolated from the rice rhizosphere zone that showed strong antagonism towards $M$. oryzae. In the present study, emphasis was placed on the field activity of $B$. amyloliquefaciens and B. pumilus as biocontrol agents of rice blast applied through seed treatment and spraying. The main objectives were to (1) screen promising Bacillus species for suppression of M. oryzae $\mathrm{P} 131$ in vitro and on detached leaves; (2) detect the biocontrol activity of Bacillus agents against rice blast under greenhouse conditions and in the field; and (3) clarify the colonization abilities of S170 and S9, determine whether the growth of the hyphae and conidia of M. oryzae P131 is inhibited by strains S170 and S9, and detect biocontrol determinants of strains S170 and S9; and (4) provide new biocontrol agents for comprehensive treatment of rice blast.

\section{Materials and Methods}

Soil sampling of rice fields. At the sites chosen for collecting soil samples, rice had been planted for several decades and there were severe occurrences of rice blast every year. Soil samples were collected from five locations in Ningxia $\left(38.26-38.91^{\circ} \mathrm{N}, 105.53-106.52^{\circ} \mathrm{E}\right)$, China. Ten soil samples were collected per location from nonrhizospheric rice soil after the harvesting of the rice. Soil samples from the same field were subsequently combined to make a composite sample. Samples were transported in an icebox to the laboratory to be further analyzed.

Isolation of bacteria. Each soil sample was serially diluted up to $10^{-8}$ with distilled water. Subsequently, $100 \mu$ of the most diluted soil re-suspension was spread on nutrient agar (NA) medium plates (1 $1 \mathrm{NA}$ medium contained $10 \mathrm{~g}$ peptone, $3 \mathrm{~g}$ beef powder, $5 \mathrm{~g} \mathrm{NaCl}$ and $15 \mathrm{~g}$ agar; the medium was made up to 11 with distilled water, $\mathrm{pH} 7.3 \pm 0.1$ ). The plates were incubated at $30^{\circ} \mathrm{C}$ for $48 \mathrm{~h}$. A quadrant streaking method was performed to isolate pure colonies of $\mathrm{Ba}$ cillus. The pure isolates were preserved in $40 \%$ glycerol at $-80^{\circ} \mathrm{C}$ for further processing.

Preparation of Bacillus, the rice blast pathogen and other phytopathogens. A virulent strain of M. oryzae P131 was provided by the Academy of Plant Protection, China Agricultural University. The fungus was grown on potato dextrose agar (PDA) medium ( 11 contains 200 g potato, $20 \mathrm{~g}$ glucose, 15-20 g agar, and sterile water was added to make $1 \mathrm{1} ; \mathrm{pH}$ neutral) at $28^{\circ} \mathrm{C}$ for 9 days and stored on PDA slants at $4^{\circ} \mathrm{C}$. There were 11 strains of other phytopathogens used to detect the antimicrobial spectrum of bacteria isolated from the soil samples. The phytopathogens that were isolated in our laboratory were Fusarium oxysporum N16-2-1, F. solani N18-1-2, and F. moniliforme N192-2. The other phytopathogens, Rhizoctonia solani RS8, F. oxysporum f. sp. niveum M8, Botrytis cinerea ZDP4, Colletotrichum gloeospoioides ZDP21, Alternaria alternate BJ-A5, A. alternate BJ-H9, Phytophthora parasitica var. nicotianae T15, and A. alternate BJ-ST24, were procured from Dr. Dianpeng Zhang (Beijing Academy of Agriculture and Forestry, China). These fungi were incubated on PDA medium at $25^{\circ} \mathrm{C}$ for 7 days and stored on PDA slants at $4^{\circ} \mathrm{C}$.

Bacillus spp. were incubated at $30^{\circ} \mathrm{C}$ for $24 \mathrm{~h}$ on NA medium plates and were cultured in Luria-Bertani (LB) medium (1 1 medium contained $10 \mathrm{~g}$ tryptone, $5 \mathrm{~g}$ beef 
extract, $10 \mathrm{~g} \mathrm{NaCl}$, and distilled water was added to make $1 \mathrm{l}$; pH 7.4-7.6) for $72 \mathrm{~h}$ at $30^{\circ} \mathrm{C}$ with shaking at $200 \mathrm{rpm}$. Next, the fermentation was centrifuged for $20 \mathrm{~min}$ at $4^{\circ} \mathrm{C}$ and $5,000 \times \mathrm{g}$. The centrifugation product was subsequently filtered using $0.22 \mu \mathrm{m}$ biofilters to obtain sterile supernatant.

Detecting antagonistic activity of Bacillus strains using leaf segment assays. The experimental rice leaf segments, which were healthy leaves from the susceptible cultivar, Ningjing no. 43 , were cut to $5 \mathrm{~cm}$ in length. In total, 90 rice leaf segments (30 for each replicate) were soaked in fermentation broths $\left(10^{8}\right.$ colony forming units $\left.[\mathrm{cfu}] / \mathrm{ml}\right)$ of strain S170 or S9 for 60 min. Another 90 leaf segments were soaked in sterile water as the control group and in Lvdikang (several Bacillus strains were mixed) as a positive control at a concentration of 100 times the diluting agent (Zhong Nong Lv Kang [Beijing] Biological Technology. Co., Ltd., Beijing, China). After $24 \mathrm{~h}$ of soaking, M. oryzae $\mathrm{P} 131$ inocula with $1 \times 10^{6}$ sporangia $/ \mathrm{ml}$ were sprayed onto the leaves using a spray bottle. Inoculated leaf segments were kept in a growth cabinet at $28^{\circ} \mathrm{C}$. They were then exposed to $85 \%$ relative humidity (RH) and a $12 \mathrm{~h}$ photoperiod for $48 \mathrm{~h}$ before the disease index (DI) was calculated.

Disease severity was defined according to the following scale (0-9): $0=$ healthy leaf, $1=$ brown spot, similar in size to a needle tip; $2=$ large brown spot; $3=$ small, round, brown necrosis scab, 1-2 $\mathrm{mm}$ in diameter; 4 = classical rice blast scab, $1-2 \mathrm{~mm}$ in diameter, the disease covers less than $2 \%$ of the leaf area; $5=$ classical rice blast scab, the disease covers less than $10 \% ; 6=$ classical rice blast scab, the disease covers from 10 to $25 \% ; 7=$ classical rice blast scab, the disease covers from 26 to $50 \% ; 8=$ classical rice blast scab, the disease covers from 51 to $75 \% ; 9=$ all leaves have died.

The DI and control efficacy were calculated according to the following formulae. $\mathrm{DI}=\sum$ (The respective disease scale $\times$ The number of leaf segments for that specific scale) $/($ The total number of leaves $\times 9) \times 100$ (La Torre et al., 2014). The control efficacy $\%=($ DI of the control group - That of the treated group) $\times 100$.

Identification of strains S170 and S9. Strains S170 and S9 were identified by analyzing $16 \mathrm{~S}$ rDNA and gyrA or gyrB gene sequences. The chloroform extraction procedure was used for DNA extraction. The bacterial universal primer pair, $27 \mathrm{~F}$ (5'-AGAGTTTGATCCTGGCTCAG-3') and $1492 \mathrm{R}$ (5'-GGTTACCTTGTTACGACTT-3'), was used to amplify the 16S rDNA gene (Kim et al., 2010). The universal primer pair was not sufficient for identify- ing the two strains. Therefore, strain S170 was identified using the gyrA F (5'-CAGTCAGGAAATGCGTACGTCCTT-3') and gyrA R (5'-CAAGGTAATGCTCCAGGCATTGCT-3') primers (Chun and Bae, 2000), and strain S9 was identified using the gyrB F (5'-TTATCTACGACCTTAGACG-3') and gyrB R (5'-TAAATTGAAGTCTTCTCCG-3') primers (Liu et al., 2013). PCR was performed using a Taq DNA polymerase kit (Majorbio Bio-Pharm Technology Co. Ltd., Shanghai, China) in 50 $\mu 1$ reactions. The PCR amplification contained several steps, including an initial denaturation step at $95^{\circ} \mathrm{C}$ for 5 min, then 30 cycles of $95^{\circ} \mathrm{C}$ for $30 \mathrm{~s}, 55^{\circ} \mathrm{C}$ for $30 \mathrm{~s}$, and $72^{\circ} \mathrm{C}$ for $90 \mathrm{~s}$, followed by a final extension step at $72^{\circ} \mathrm{C}$ for $10 \mathrm{~min}$. The DNA sequences of the PCR products were blasted in the GenBank (Bethesda, MD, USA; http://www. ncbi.nlm.nih.gov/). The gene sequences were then analyzed with CLUSTAL 2.0 (Thompson et al., 1997) and Mega 5.0 using the neighbor-joining method (Kim et al., 1993).

The antagonistic activity of strains S170 and S9 against the 12 phytopathogens. A dual culture method was used to assess the spectrum of antagonistic activity of strains S170 and S9 against the 12 phytopathogens described in section 2.3, on PDA plates (Sha et al., 2016a). A pathogen disk ( $1 \mathrm{~cm}$ in diameter) was placed in the center of each plate $(9 \mathrm{~cm}$ in diameter), and the antagonistic disk $(0.5$ $\mathrm{cm}$ in diameter) of the Bacillus strain was then put $2.0 \mathrm{~cm}$ away from the pathogen disk. No antagonistic disk was placed in the plate used as the control. Each treatment was replicated on 10 plates and repeated three times. All plates were incubated at $25^{\circ} \mathrm{C}$ under dark conditions. The antagonistic activity was assessed as the inhibition rate against mycelial radial growth. The antagonistic activity was then calculated using the following formula: [(The mycelial radial growth of the pathogen in the control - The mycelial radial growth of the pathogen inhibited by Bacillus strains)/ The mycelial radial growth of the pathogen in the control] $\times 100$.

The biocontrol ability of strains S170 and S9 in the greenhouse and field. Rice seeds of the Ningjing no. 43 variety were soaked in $1 \%$ sodium hypochlorite solution for $20 \mathrm{~min}$ and then washed three times with $70 \%$ ethanol and five times with sterile water. After keeping seeds in a petri dish in a growth chamber at $28^{\circ} \mathrm{C}$ for 2 days, the germinated seeds were transplanted into a pot in the greenhouse. When the rice plants had grown for 30 days in the greenhouse $\left(28^{\circ} \mathrm{C}\right.$ and $\left.65 \% \mathrm{RH}\right)$, each treatment (encompassing 30 rice plants each) was sprayed with $50 \mathrm{ml}$ of fermentation broth generated from S170 and S9 (at $10^{8} \mathrm{cfu} /$ 
$\mathrm{ml}$ ). For the negative control, 30 rice plants were sprayed with sterile water. After $24 \mathrm{~h}$, all test plants were sprayed with a suspension of $M$. oryzae P131 (at $\left.10^{6} \mathrm{cfu} / \mathrm{ml}\right)$. The disease severity of the rice leaf blast was investigated 7 days post inoculation. The experiments were repeated three times.

According to the field trial standard GB/T17980.19-2000 formulated by the Chinese Ministry of Agriculture based on the European Plant Protection Organization (EPPO) and Food and Agriculture Organization (FAO) guidelines, the control efficacies of strains S170 and S9 were detected over three successive years (2017-19) in in Yaofu town, Pingluo county, China $\left(38.91^{\circ} \mathrm{N}, 106.52^{\circ} \mathrm{E}\right)$ (Kumar et al., 2017; Sha et al., 2016a). The field trials were designed in a completely randomized block and each treatment involved four replicates. The average test area for each replicate was approximately $50 \mathrm{~m}^{2}$. Rice seeds were soaked in a suspension of $\mathrm{S} 170$ or $\mathrm{S} 9$ (at $10^{8} \mathrm{cfu} / \mathrm{ml}$ ) for $1 \mathrm{~h}$ before planting, and chemical fungicides were not applied during the growing seasons.

Using a backpack sprayer, 2.51 of S170 suspension or S9 suspension (at $10^{8} \mathrm{cfu} / \mathrm{ml}$ ) was sprayed on each replicate. Each replicate was sprayed five times during the growing season. The sprays were performed at the seedling stage, the tillering stage, the booting stage, the rupturing stage and the full heading stage; rice plants sprayed with water were used as the control group. Tricyclazole wettable powder $(75 \%)$ was sprayed at a concentration of $1.05-1.20 \mathrm{~kg} / \mathrm{hm}^{2}$; water 600-750 kg (Dow Agro Sciences Co., Ltd., Beijing, China) was used as a chemical control and Lvdikang was used as a biological control and applied at a concentration of 100 times the diluting agent. Disease assessment was performed, as described above, for the leaf blast and panicle neck blast, which were investigated at the tillering stage and harvest stage, respectively. For the investigation of leaf blast, individual leaves from four test areas were randomly selected. For the panicle neck blast investigation, 100 rice panicles from 20 plots in four test areas were randomly selected.

The grading standard for panicle neck blast was as follows: $0=$ no panicle neck blast, grain blast or branch blast; $1=$ only grain blast and branch blast, less than $5 \%$ of grains empty; 2 = only grain blast and branch blast, 6 to $10 \%$ of grains empty; $3=$ only grain blast and branch blast, 11 to $20 \%$ of grains empty; $4=$ only grain blast and branch blast, 21 to $30 \%$ of grains empty; $5=$ panicle neck blast, grain blast and branch blast, 31 to $80 \%$ of grains empty; and $6=$ panicle neck blast, more than $80 \%$ of grains empty.

The DI and control efficacy were calculated according to the following formulae. DI $=[\Sigma$ (Rice blast rating $\times$ Num- ber of panicles at that rating)/(Total number of rice panicles investigated $\times 9)] \times 100$. Control efficacy $\%=[(\mathrm{DI}$ of the control - DI of the treatment)/DI of the control] $\times 100$.

The observed antagonistic effects of strains S170 and S9 using scanning electron microscopy (SEM). For the SEM examination, a disk $(1 \mathrm{~cm}$ in diameter) of $M$. oryzae P131 was placed in the center of each plate $(9 \mathrm{~cm}$ in diameter) containing 15-20 ml PDA medium. The antagonistic disk $(0.5 \mathrm{~cm}$ in diameter) of S170 or S9 was then placed $2.0 \mathrm{~cm}$ away from the pathogen disk. No antagonistic disk was placed in the plate used as the control. Each treatment was replicated on 10 plates and repeated three times. All plates were incubated at $25^{\circ} \mathrm{C}$ under dark conditions. After 5 days, the antagonistic zones inhibited by $B$. amyloliquefaciens $\mathrm{S} 170$ and B. pumilus $\mathrm{S} 9$ were cut into $2 \mathrm{~mm}$ strips to observe the hyphal structure of $M$. oryzae P131. The outer edges of M. oryzae P131 in the control plates were cut into $2 \mathrm{~mm}$ strips. To facilitate this analysis, all strips were fixed in 4\% glutaraldehyde, dehydrated, and coated with gold (Kong et al., 2012). The hyphal structure of M. oryzae P131 was observed using an S-3400N (Hitachi, Tokyo, Japan) scanning electron microscope (Kong et al., 2012).

Bioactive substances produced by strains S170 and S9. The bioactive substances produced by $B$. amyloliquefaciens $\mathrm{S} 170$ and $B$. pumilus $\mathrm{S} 9$, such as proteases, amylases, siderophores, cellulases, $\beta$-1,3-glucanases and volatile substances, were quantified. Protease and cellulose activities were determined according to protocols published by Abraham et al. (2013), Kumar et al. (2017), and Shakeel et al. (2015); $\beta$-1,3-glucanase activity was assayed using a protocol published by Nagpure et al. (2014). Siderophore production was tested for using a chrome azurol $\mathrm{S}$ assay published by Schwyn and Neilands (1987). Amylase activity was determined for each step using a method published by Shaldon (1956). The antifungal activities of the volatile substances were determined using a procedure published by Arrebola et al. (2010).

Relative inhibition rate $\%=[($ The mycelium diameter for the empty control - The mycelium diameter for the test bacteria)/The mycelium diameter of the empty control] $\times$ 100.

Stem colonization ability of GFP-tagged S170 and S9. Electrocompetent Bacillus cells were prepared as previously described by Sha et al. (2016b). The cells were grown in $\mathrm{LB}$ medium at $30^{\circ} \mathrm{C}$. The pellets were harvested during the exponential growth phase by centrifugation at $8,000 \times \mathrm{g}$ for $10 \mathrm{~min}$ at $4^{\circ} \mathrm{C}$. The pellets were subsequently washed five 
times with an equal volume of cold electroporation buffer containing $0.5 \mathrm{M}$ sorbitol, $0.5 \mathrm{M}$ mannitol and $10 \%$ glycerol (pH 7). The green fluorescent protein (GFP) plasmid pGFP78 (100 mg) was added to the suspension of Bacillus cells $(100 \mathrm{ml})$ and immediately exposed to a $1.8 \mathrm{kV}$ electric shock. The entire electroporation process was carried out on ice. After electroporation, the cell suspension was diluted with $1 \mathrm{ml}$ of LB medium containing $0.5 \mathrm{M}$ sorbitol and $0.38 \mathrm{M}$ mannitol and was subsequently incubated at $37^{\circ} \mathrm{C}$ while shaking at $160 \mathrm{rpm}$ for $3 \mathrm{~h}$ to facilitate the expression of antibiotic resistance markers. Aliquots were spread onto LB plates containing tetracycline $(10 \mathrm{~g} / \mathrm{ml})$. Cells with green fluorescence were used for the following experiments.

The GFP-tagged S170 and S9 strains were prepared in LB liquid medium in a shaker at $200 \mathrm{rpm}$ at $30^{\circ} \mathrm{C}$ for 2 days. Cells were re-suspended in sterile water to adjust the density to $10^{8} \mathrm{cfu} / \mathrm{ml}$. The suspensions were sprayed onto the stem and leaf surface of 20-day-old G19 cultivars growing in a greenhouse. Other plants sprayed with sterile
Table 1. Biocontrol effect of isolates S170 and S9 on rice blast in leaf disk assays

\begin{tabular}{lcc}
\hline Treatment $^{\mathrm{a}}$ & Disease index $^{\mathrm{b}}$ & Antifungal efficacy (\%) \\
\hline S170 & $7.5 \pm 0.3 \mathrm{~b}$ & $75.5 \pm 0.7$ \\
S9 & $7.6 \pm 0.2 \mathrm{~b}$ & $74.6 \pm 1.1$ \\
Lvdikang & $7.1 \pm 0.4 \mathrm{~b}$ & $76.2 \pm 1.1$ \\
Water control & $29.6 \pm 0.6 \mathrm{a}$ & - \\
\hline
\end{tabular}

Values are presented as mean \pm standard error.

${ }^{\mathrm{a}}$ The concentration of the S170 and S9 inoculums was $1 \times 10^{8}$ colony forming units $/ \mathrm{ml}$.

${ }^{\mathrm{b}}$ The disease index was determined $72 \mathrm{~h}$ after Magnaporthe oryzae P131 inoculation. Values are representative of three experiments, and four replicates were used for each experiment. Different letters indicate significant differences according to a Student's $t$-test $(P<0.05)$.

water were used as controls. Each treatment involved six replicates (feeding block), and the experiment was repeated twice. The stems ( $3 \mathrm{~cm}$ from the base) were collected 5 days after inoculation for all treatments. Stem tissue was sliced by cryosectioning to generate sections with a
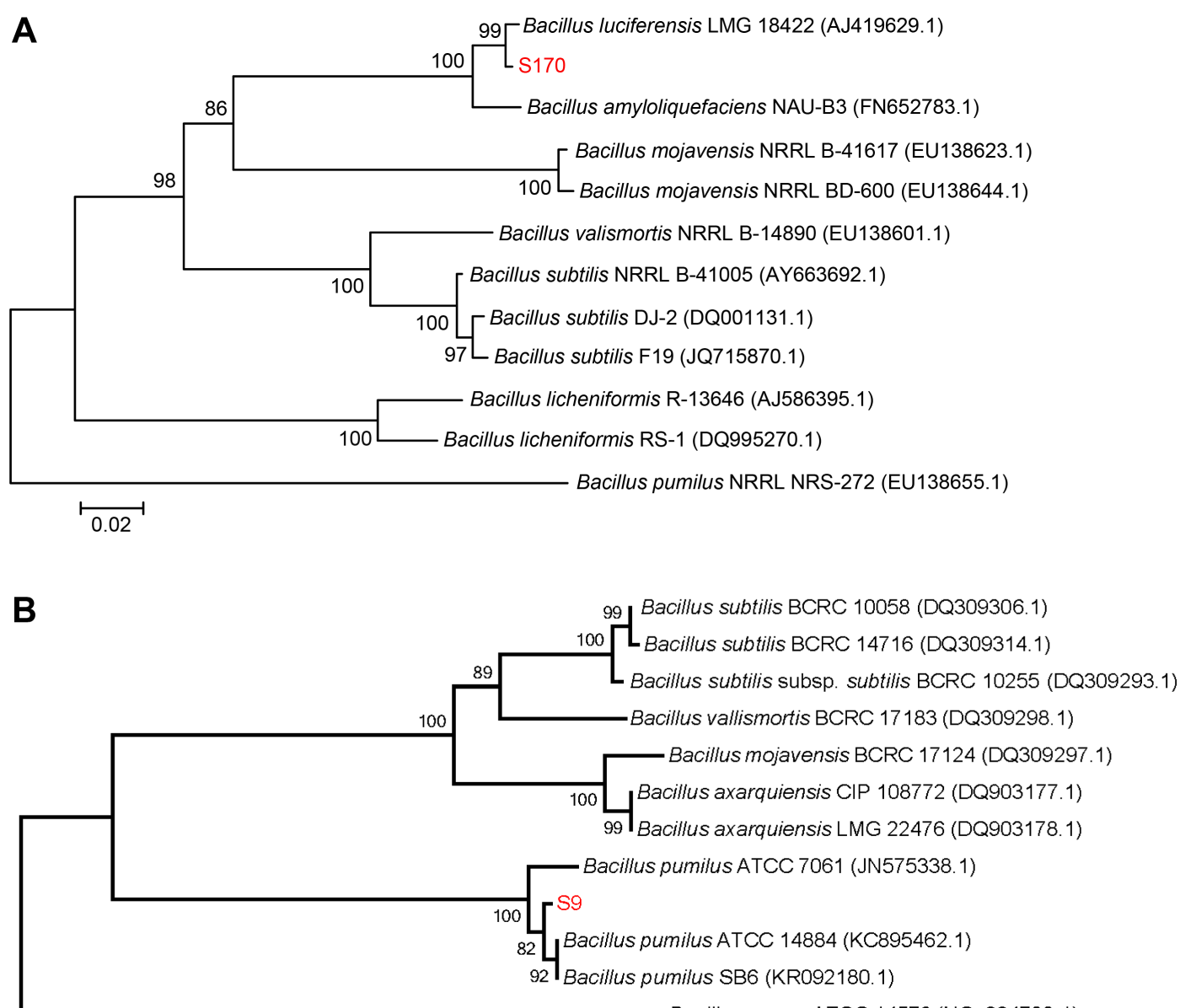

Fig. 1. Phylogenetic tree generated based on the gyrA gene sequence indicating the position of strain S170 (using the neighbor-joining method) (A) and on the gyrB gene sequence indicating the position of strain S9 (using the neighborjoining method) (B). 
thickness of $20 \mathrm{~mm}$. The slides were viewed directly using a confocal scanning laser microscope (CSLM; Leica Fluoview TCSSP8, Leica Microsystems Ltd., Wetzlar, Germany) with an excitation wavelength of $488 \mathrm{~nm}$.

Statistical analysis. Each analysis was carried out using the least significant difference test $(P<0.05)$ following one-way analysis of variance (ANOVA) using SPSS ver. 19.0 software for Windows (SPSS Inc., Chicago, IL, USA).

\section{Results}

Screening Bacillus isolates using leaf disk assays. A total of 232 bacterial strains were isolated from nonrhizospheric rice soil. All of the isolates were screened for the ability to control rice blast using the leaf disk assay. There were 15 bacterial isolates showing fungal activity against $M$. oryzae $\mathrm{P} 131$ on detached leaves. In particular, isolates S170 and S9 evidently inhibited rice blast from 1 to 3 days after inoculation, especially on day 2 . The DI values of leaves treated by isolates $\mathrm{S} 170$ or $\mathrm{S} 9$ were significantly lower than those of the leaves of the water control group. The control efficacy of the isolates $\mathrm{S} 170$ and $\mathrm{S} 9$ was $75.5 \%$ and $74.6 \%$, respectively (Table 1). There were no differences in the DI between experimental isolates in the control group and the Lvdikang control group.

Identification of strains S170 and S9. Based on 16S rDNA sequence alignments, S170 (KY264994 in the National Center for Biotechnology Information [NCBI]) had a high similarity with $B$. amyloliquefaciens, while S9 (KY264956 in NCBI) was highly similar to B. pumilus.

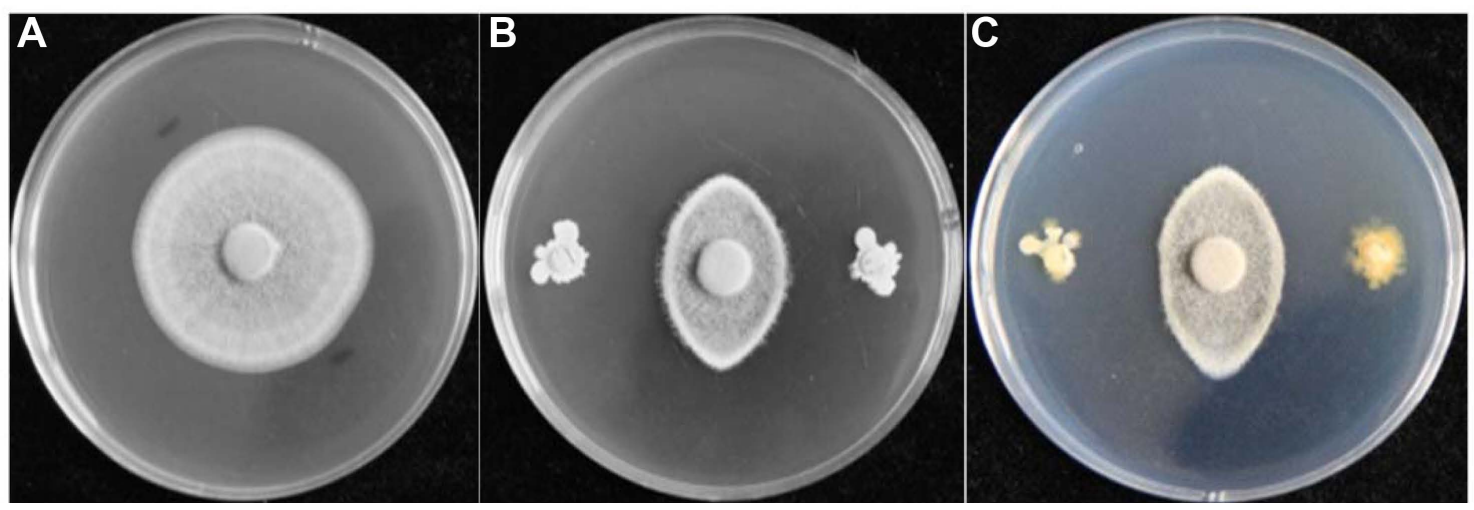

Fig. 2. The mycelial growth rate of Magnaporthe oryzae P131 is inhibited by antagonistic bacteria. The mycelia of M. oryzae P131 (A); and the mycelia of M. oryzae P131 inhibited by strains S170 (B) and S9 (C).

Table 2. Antagonist activity of isolates S170 and S9 against various fungal plant pathogens in vitro

\begin{tabular}{|c|c|c|c|}
\hline \multirow{2}{*}{ Target fungal pathogens } & \multirow{2}{*}{ Host } & \multicolumn{2}{|c|}{ Inhibitory activity } \\
\hline & & S170 & S9 \\
\hline Magnaporthe oryzae $\mathrm{P} 131$ & Rice & ++++ & ++++ \\
\hline Fusariumoxy sporum N16-2-1 & Potato & +++ & + \\
\hline Fusarium solani $\mathrm{N} 18-1-2$ & Potato & + & - \\
\hline Fusarium moniliforme N1-2-2 & Potato & + & - \\
\hline Rhizoctonia solani $\mathrm{RS} 8$ & Wheat & ++ & ++ \\
\hline Botrytis cinerea ZDP4 & Tomato & + & + \\
\hline Colletotrichum gloeosporioides ZDP21 & Strawberry & ++++ & + \\
\hline Alternaria alternata BJ-A 5 & Apple & +++ & ++ \\
\hline Alternaria alternata BJ-ST24 & Strawberry & ++++ & +++ \\
\hline Alternaria alternata BJ-H9 & Chinese flowering crabapple & ++++ & +++ \\
\hline Fusarium oxysporum f. sp. niveum M8 & Watermelon & +++ & + \\
\hline Phytophthora parasitica var. nicotianae T15 & Tobacco & +++ & + \\
\hline
\end{tabular}

,,+++++ , and ++++ represent relative mycelial growth inhibition rates for each fungal colony on potato dextrose agar medium. Inhibition rates were recorded as follows:,$+ 50-60 \%$; ++, 61-70\%; +++, 71-80\%; and ++++, $>80 \%$. - represents no inhibition rates. 
Sequencing the gyrA and gyrB genes revealed that $\mathrm{S} 170$ had $100 \%$ correspondence with B. amyloliquefaciens NAU-B3 and S9 had $100 \%$ correspondence with $B$. pumilus ATCC7061. Phylogenetic trees were constructed using the gyrA gene sequence for S170 (Fig. 1A), and the gyrB gene sequence for S9 (Fig. 1B). The results clearly showed that strain S170 clustered with B. amyloliquefaciens strains while strain S9 clustered with B. pumilus strains. Taken together, these results suggest that $\mathrm{S} 170$ is a $B$. amyloliquefaciens strain, while $\mathrm{S} 9$ is a $B$. pumilus strain.

The antagonistic activity of strains S170 and S9 against 12 phytopathogens. Strains S170 and S9 significantly inhibited the growth of the mycelia of M. oryzae P131 on PDA medium plates (Fig. 2). Moreover, both strains exhibited broad-spectrum antagonistic activities against 11 other pathogens in vitro (Table 2). Strains S170 and S9 evidently suppressed the growth of Fusarium oxysporum, F. solani, F. moniliforme, Rhizoctonia solani, Botrytis cinerea, Colletotrichum gloeospoioides, Alternaria alternate, F. oxysporum
Table 3. Control efficacy of S170 and S9 against rice blast under greenhouse conditions

\begin{tabular}{lcc} 
Treatment $^{\mathrm{a}}$ & Disease index $^{\mathrm{b}}$ & Control efficacy (\%) \\
\hline S170 & $5.1 \pm 1.2 \mathrm{~b}$ & $76.9 \pm 0.5$ \\
S9 & $5.5 \pm 0.8 \mathrm{~b}$ & $75.1 \pm 0.9$ \\
Lvdikang & $5.0 \pm 1.1 \mathrm{~b}$ & $77.4 \pm 1.1$ \\
Water control & $22.1 \pm 2.4 \mathrm{a}$ & - \\
\hline
\end{tabular}

Values are presented as mean \pm standard error.

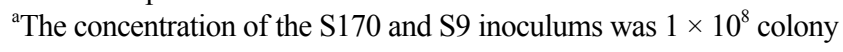
forming units $/ \mathrm{ml}$.

${ }^{\mathrm{b}}$ The disease index was determined 7 days after Magnaporthe oryzae P131 inoculation. Values are representative of three experiments, and four replicates were used for each experiment. Different letters indicate significant differences according to the Student's $t$-test $(P<0.05)$.

f. sp. niveum, and Phytophthora parasitica var. nicotianae, which cause rice sheath blight, tomato gray mold, strawberry anthracnose, apple leaf blight, begonia leaf blight, watermelon wilt disease and tobacco black shank. Isolate S170 showed a broader antagonistic spectrum than isolate S9.

Table 4. Control efficacy of strains S170 and S9 against rice leaf blast in the field

\begin{tabular}{lrcrrrr}
\hline & \multicolumn{2}{c}{2017} & \multicolumn{2}{c}{2018} & \multicolumn{2}{c}{2019} \\
\cline { 2 - 7 } Treatment $^{\mathrm{a}}$ & Disease index & $\begin{array}{c}\text { Control efficacy } \\
(\%)^{\mathrm{b}}\end{array}$ & Disease index & $\begin{array}{c}\text { Control efficacy } \\
(\%))^{\mathrm{b}}\end{array}$ & $\begin{array}{c}\text { Disease index } \\
\text { Control efficacy } \\
(\%)^{\mathrm{b}}\end{array}$ \\
\cline { 2 - 7 } & $8.5 \pm 0.5 \mathrm{~b}$ & $73.2 \pm 1.1$ & $2.9 \pm 0.8 \mathrm{~b}$ & $91.1 \pm 1.7$ & $7.1 \pm 1.1 \mathrm{~b}$ & $84.8 \pm 1.2$ \\
S9 & $9.4 \pm 1.2 \mathrm{~b}$ & $70.6 \pm 1.3$ & $7.1 \pm 1.4 \mathrm{~b}$ & $79.3 \pm 1.6$ & $13.1 \pm 2.7 \mathrm{~b}$ & $71.9 \pm 3.4$ \\
Biological control & $7.8 \pm 0.3 \mathrm{~b}$ & $75.6 \pm 0.7$ & $4.1 \pm 1.7 \mathrm{~b}$ & $88.7 \pm 2.4$ & $16.4 \pm 1.3 \mathrm{~b}$ & $64.9 \pm 1.9$ \\
Chemical control & $8.4 \pm 0.2 \mathrm{~b}$ & $73.5 \pm 2.1$ & $9.7 \pm 2.5 \mathrm{~b}$ & $72.2 \pm 2.1$ & $11.8 \pm 2.2 \mathrm{~b}$ & $74.7 \pm 1.9$ \\
Water control & $31.8 \pm 0.3 \mathrm{a}$ & - & $36.2 \pm 2.1 \mathrm{a}$ & - & $46.7 \pm 2.1 \mathrm{a}$ & - \\
\hline
\end{tabular}

Values are presented as mean \pm standard error.

${ }^{a}$ The concentration of the S170 and S9 inoculums was $1 \times 10^{8}$ colony forming units $/ \mathrm{ml}$.

${ }^{b}$ The disease index of leaf blast was determined at the tillering stage of rice. Values are representative of five experiments, and four replicates were used for each experiment. Different letters indicate significant differences according to the Student's $t$-test $(P<0.05)$.

Table 5. Control efficacy of strains S170 and S9 against rice panicle blast in the field

\begin{tabular}{|c|c|c|c|c|c|c|}
\hline \multirow[b]{2}{*}{ Treatment $^{\mathrm{a}}$} & \multicolumn{2}{|c|}{2017} & \multicolumn{2}{|c|}{2018} & \multicolumn{2}{|c|}{2019} \\
\hline & Disease index & $\begin{array}{c}\text { Control efficiency } \\
(\%)^{\mathrm{b}}\end{array}$ & Disease index & $\begin{array}{c}\text { Control efficiency } \\
(\%)^{\mathrm{b}}\end{array}$ & Disease index & $\begin{array}{c}\text { Control efficiency } \\
(\%)^{\mathrm{b}}\end{array}$ \\
\hline $\mathrm{S} 170$ & $11.8 \pm 0.7 \mathrm{~b}$ & $74.8 \pm 0.4$ & $14.8 \pm 0.7 b$ & $72.0 \pm 1.1$ & $5.3 \pm 0.7 b$ & $78.4 \pm 2.3$ \\
\hline S9 & $13.3 \pm 0.3 \mathrm{~b}$ & $71.6 \pm 0.3$ & $15.3 \pm 0.3 \mathrm{~b}$ & $71.1 \pm 0.9$ & $6.8 \pm 3.8 b$ & $72.2 \pm 0.9$ \\
\hline Biological control & $12.3 \pm 0.7 \mathrm{~b}$ & $76.3 \pm 0.4$ & $15.1 \pm 1.8 \mathrm{~b}$ & $71.5 \pm 1.5$ & $6.6 \pm 1.3 \mathrm{~b}$ & $73.1 \pm 1.5$ \\
\hline Chemical control & $12.1 \pm 0.5 b$ & $74.2 \pm 1.1$ & $15.4 \pm 1.2 \mathrm{~b}$ & $70.9 \pm 1.3$ & $6.1 \pm 0.9 \mathrm{~b}$ & $75.1 \pm 1.3$ \\
\hline Water control & $46.9 \pm 3.1 \mathrm{a}$ & - & $52.9 \pm 2.3 \mathrm{a}$ & - & $24.5 \pm 1.3 \mathrm{a}$ & - \\
\hline
\end{tabular}

Values are presented as mean \pm standard error.

${ }^{a}$ The concentration of the S170 and S9 inoculums was $1 \times 10^{8}$ colony forming units $/ \mathrm{ml}$.

${ }^{\mathrm{b}}$ The disease index of panicle neck blast was determined at the yellow ripening stage of rice. Values are representative of five experiments, and four replicates were used for each experiment. Different letters indicate significant differences according to the Student's $t$-test $(P<0.05)$. 
The biocontrol activity assays of strains S170 and S9. Under greenhouse conditions, strains S170 and S9 exhibited strong antifungal activity following the controlled $M$. oryzae infection (Table 3). There was a 5.2-fold reduction in DI in the S170-treated group and a 4.2-fold reduction in $\mathrm{DI}$ in the S9-treated group compared with the water control. There were no differences in DI between the control group and the Lvdikang control group.

The ability of strains S170 and S9 to suppress rice blast were tested in the field between 2017 and 2019 (Tables 4 and 5). In 2017, a small-scale experiment was conducted and both strains evidently suppressed $M$. oryzae infection. To confirm their biocontrol ability, both a small-scale and larger scale experiments were conducted in 2018 and 2019. The results of these 3-year studies revealed 8.1- and 3.8fold reductions in DI in the S170-treated group compared with the water control group for leaf blast and panicle neck blast, respectively. Treatment with S9 resulted in a 4.2- and
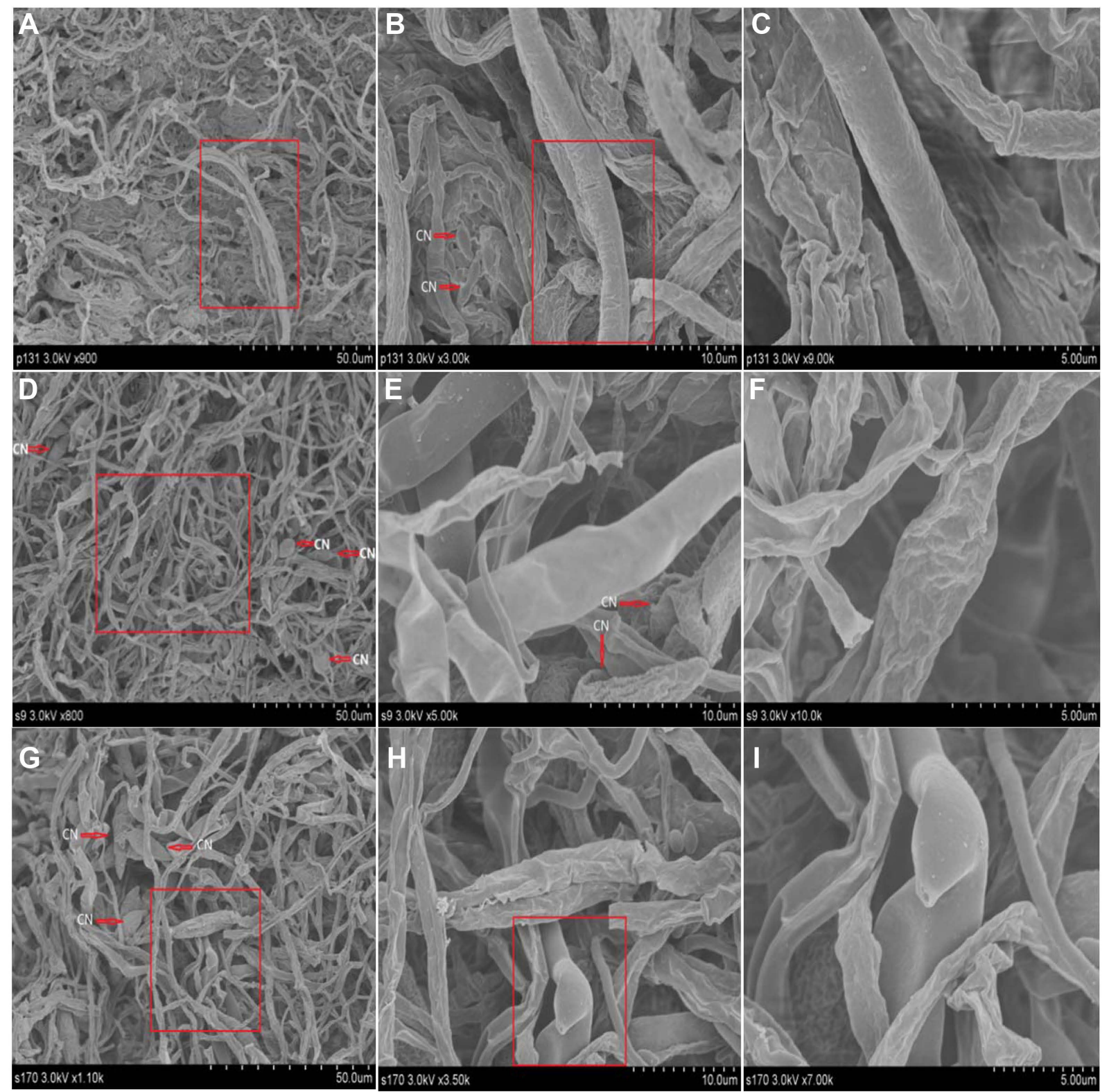

Fig. 3. Scanning electron microscope analysis of Magnaporthe oryzae P131. (A-C) The normal hyphae and conidia of M. oryzae P131. (D-F) The hyphae and conidia of M. oryzae P131 inhibited by Bacillus pumilus S9. (G-I) The hyphae and conidia of M. oryzae P131 inhibited by B. amyloliquefaciens S170. CN represents the conidia of M. oryzae P131, red arrows point to conidia, and the boxes surround hyphae of typical morphology. 
Table 6. Bioactive substances produced by S170 and S9

\begin{tabular}{lcccccc}
\hline Strains & Protease & Amylase & Cellulose & Siderophore & Glucanase & Volatile substances \\
\hline S170 & + & + & + & + & - & - \\
S9 & + & - & + & + & - & + \\
\hline
\end{tabular}

+ , the production of the biocontrol-related substance by the test strain; -, a lack of production of the biocontrol-related substance by the test strain.

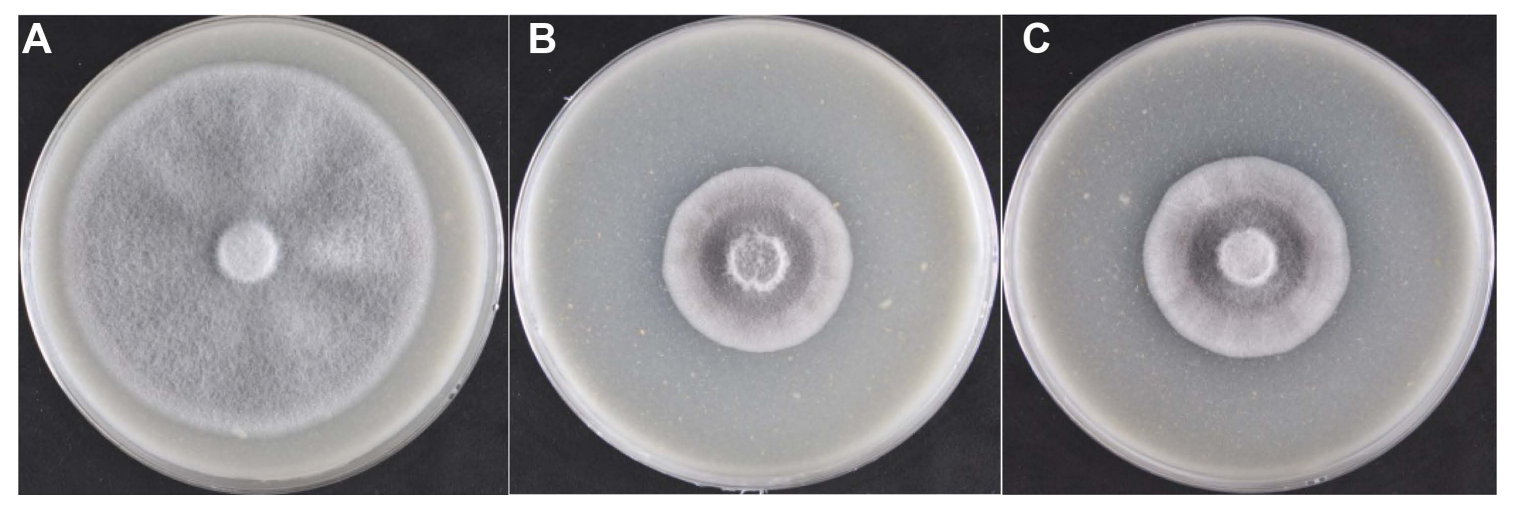

Fig. 4. The inhibitory activity of volatile substances produced by test strains. The normal mycelia of Magnaporthe oryzae P131 (A); and the mycelia of $M$. oryzae P131 inhibited by volatile substances produced by strains S9 (B) and S170 (C).

3.5-fold reduction in DI, respectively. It was observed that disease injuries were effectively controlled following application of either strain along with both chemical and biological fungicides during the growing season. These results suggest that both strains can effectively control $M$. oryzae infection in field conditions.

SEM analysis of M. oryzae P131 inhibition by strains S170 and S9. The hyphae of M. oryzae P131 that were not treated with antagonistic bacteria were completely tubular in shape and were morphologically normal when observed by SEM (Fig. 3A-C). Hyphae that were treated with $B$. pumilus strain $\mathrm{S} 9$ displayed swelling and partial distortion (Fig. 3D-F). The hyphae treated with B. amyloliquefaciens strain S170 showed shrinkage, partial distortion, roughness, hollowness and wrinkling of the surface, indicating overall morphological abnormality (Fig. 3G-I).

The conidia of $M$. oryzae P131 that were not exposed to antagonistic bacteria formed morphologically normal appressoria, as observed under SEM (Fig. 3B). After exposure to B. pumilus strain $\mathrm{S} 9$ and B. amyloliquefaciens strain S170, the cell walls of the conidia appeared to be severely degraded (Fig. 3D and G).

Overall, the cells of $M$. oryzae P131 treated with $B$. pumilus strain S9 and B. amyloliquefaciens strain S170 exhibited abnormal morphology and cellular disorganization, suggesting that S9 and S170 degrade the cell wall, destroy the cell membrane and damage cellular organelles.

Detection of bioactive substances of strains S170 and S9. Based on the transparent zone observed after each treatment, it was possible to analyze biocontrol determinants (Table 6). Following this analysis, B. amyloliquefaciens S170 and B. pumilus S9 were observed to produce proteases, amylases, cellulases and volatile substances. Strain S9 also produced siderophores. The relative inhibition ratios of the volatile substances produced by strains S170 and S9 were $56.25 \%$ (Fig. 4B) and $61.11 \%$ (Fig. 4C), respectively.

Colonization ability of S170 and S9. To detect the colonization abilities of S170 and S9, GFP-tagged strains were sprayed onto stems of rice planted in a greenhouse. These plants were examined by CSLM 7 days later. The results revealed that the GFP-tagged cells were easily observed between the epidermis and ground tissues of the treated stems (Fig. 5C and E). The parenchymatous tissues of the stems were observed using fluorescence microscopy (Fig. 5D and F), whereas no fluorescence was observed in the control stems (Fig. 5A and B). These results suggest that both soil bacterial strains were capable of colonizing rice stems.

\section{Discussion}

At present, some strains have been applied to control 

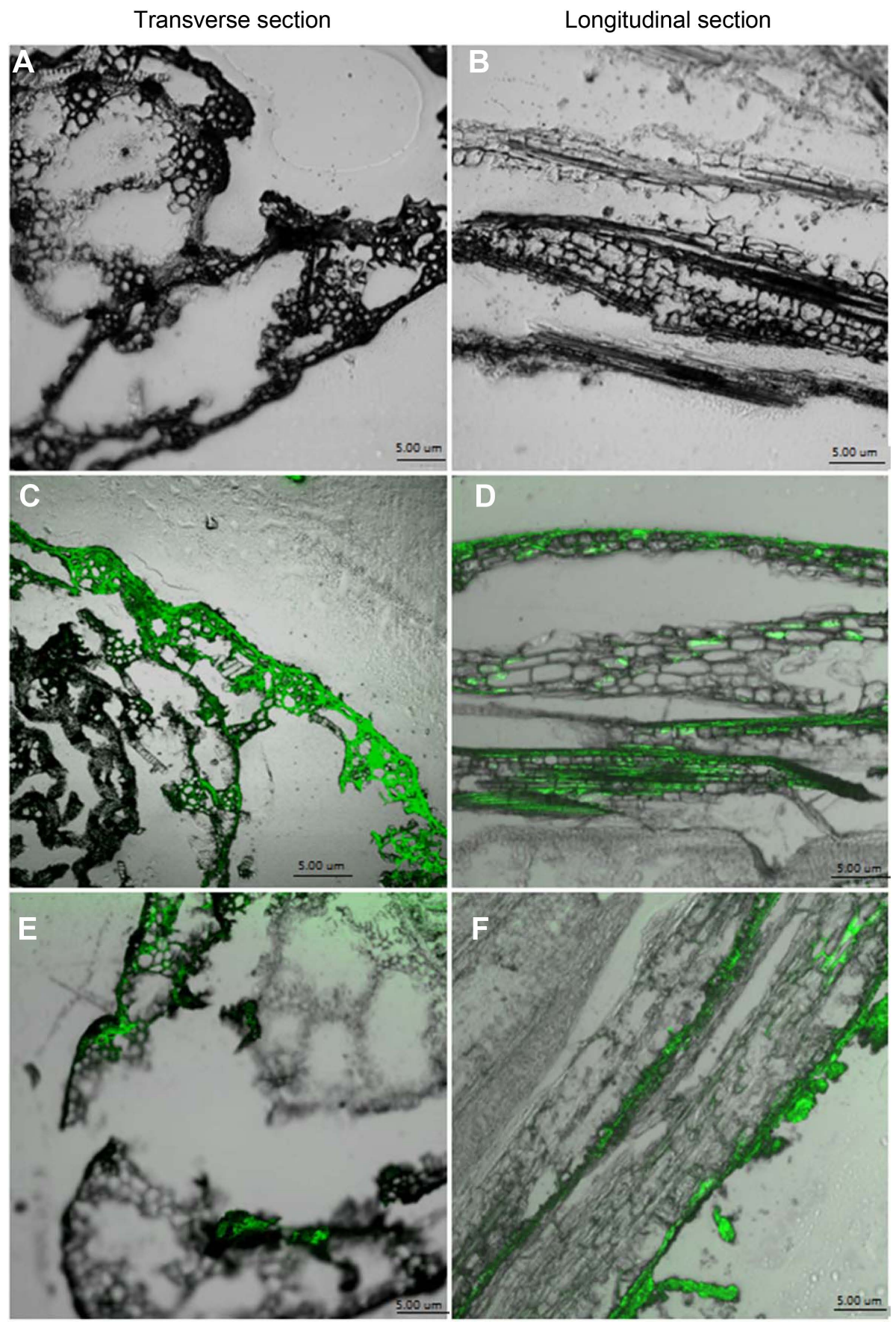

Fig. 5. Confocal microscopy images of rice stems inoculated with GFP-tagged strains. Transverse and longitudinal sections of the rice stems of the control group treated with sterile water (A, B); and of the rice stems treated with GFPtagged S9 (C, D) and GFP-tagged S170 $(\mathrm{E}, \mathrm{F})$.

rice blast for sustainable agricultural development. These strains include B. subtilis, B. cereus, B. amyloliquefaciens, B. pumilus, B. licheniformis, and Paenibacillus polymyxa. Due to their evident ability to control many plant pathogens, promote plant growth and enhance crop yield, plantgrowth-promoting rhizobacteria have become the main research focus for an increasing number of plant pathologists. Rais et al. $(2016,2018)$ screened Bacillus strains isolated from the rice rhizosphere in Pakistan, such as KEF-5, KEF-
7, KEF-12, KEF-17, and KEF-18, which showed strong antifungal activity towards to $M$. oryzae and enhanced rice yield. B. subtilis strain UASP17, isolated from the rice rhizosphere in India by Kumar et al. (2017), evidently reduced blast severity. There are many reports about Bacillus spp. isolated from the rhizosphere that act against rice blast. However, few studies have reported on the strains isolated from nonrhizospheric rice soil.

In order to enrich biocontrol sources, our team isolated 
Bacillus spp. with high control activity against $M$. oryzae and other plant pathogens from nonrhizospheric soil from rice fields in Northwest China. In a previous study, 17 out of 232 soil isolates exhibited potential to stimulate rice seedling growth; the same isolates promoted grain quality at the harvest stage (Sha et al., 2018). In the current study, a leaf disk assay revealed that two isolates showed significant promise in suppressing disease severity following M. oryzae infection under field conditions. These isolates, S170 and S9, could therefore be potentially used for the biocontrol of $M$. oryzae. Their suppressive activity suggests a prospect for practical applications in the sustainable development of rice farming.

Based on 16S rDNA, and gyrA, and gyrB gene sequence analyses, strains $\mathrm{S} 170$ and $\mathrm{S} 9$ were identified as B. amyloliquefaciens and B. pumilus, respectively. Strain S9 was identified by amplifying the gyrA and gyrB genes, but the gyrA gene amplification failed. Both of these species also produce bioactive compounds (Chen et al., 2016) and promote plant growth. Until now, $B$. amyloliquefaciens and $B$. pumilus have been considered to be environmentally friendly agents with effective inhibition activity against numerous plant pathogens.

In the present study, B. amyloliquefaciens $\mathrm{S} 170$ and $B$. pumilus $\mathrm{S} 9$ exhibited broad-spectrum antibacterial activity. The plant pathogens studied cause disease in different plants including potato, wheat, rice, watermelon, strawberry, apple, begonia and tobacco. The application of $B$. amyloliquefaciens $\mathrm{S} 170$ had a greater biocontrol ability than that of B. pumilus $\mathrm{S} 9$.

Bacillus species can indirectly inhibit phytopathogens through biocontrol strategies including the repossession of pathogenic iron by siderophores, the production of hydrolytic enzymes to degrade pathogenic cell walls, and the production of antibiotics to interfere with pathogenic respiration (Ahmad et al., 2017; Li et al., 2014; Li et al., 2017; Qi et al., 2017; Zhang and Sun, 2018). Huang et al. (2020) isolated B. cereus HS24 from a rice farm; B. cereus HS24 could significantly reduce conidium germination by interfering with the $M$. oryzae $\mathrm{Ca}^{2+}$ signaling pathway. SEM analysis revealed that $B$. amyloliquefaciens $\mathrm{S} 170$ and $B$. pumilus S9 degraded the hyphae and conidial cell walls of M. oryzae P131. The same strains caused partial mycelial morphology inflation or crimp, and few appressoria and germinal tubes in M. oryzae. It is possible that hydrolytic enzymes and antibiotic production in strains S170 and S9 degraded cell walls and inhibited pathogenic growth. It is not clear what antibiotics B. amyloliquefaciens $\mathrm{S} 170$ and B. pumilus S9 produce, and a follow-up study will be performed to purify and study the characteristics of the me- tabolites of the two strains.

Bacillus spp. can produce enzymes such as chitinase, $\beta$-1,3-glucanase and peroxidase, that can dissolve the cell wall of $M$. oryzae, or suppress conidium germination and appressorium formation. For example, B. subtilis NSRS 89-24 has been shown to produce $\beta-1,3$-glucanase, and thus, could significantly inhibit the growth of $M$. oryzae (Leelasuphakul et al., 2006). Meanwhile, B. subtilis KB1122 produced tyrosine, serine and threonine kinases to cause germ tube abnormality, cell wall rupture, and mycelium collapse in M. oryzae (Zhang et al., 2014). In the present study, B. amyloliquefaciens S170 also produced proteases, amylases and cellulases. B. pumilus $\mathrm{S} 9$ produced siderophores, proteases, amylases and cellulases. However, the latter strain did not form biofilms to enhance colonization in rice plants. After following the two-sealed-baseplates method, the results indicated that volatile substances isolated from strains S170 and S9 exhibited antifungal activity towards $M$. oryzae.

Plant colonization by bacteria is deemed a key characteristic in the interaction between these bacterial species and pathogens (Huang et al., 2011). Ji et al. (2014) reported that B. subtilis CB-05, which is a gram-positive diazotrophic endophytic bacterium, can effectively colonize rice roots. Liu et al. (2006) reported that B. megaterium $\mathrm{C} 4$, which is a gram-negative diazotrophic rhizospheric bacterium, can also colonize rice roots. The colonization abilities of GFPtagged S170 and S9 in the rice stem were demonstrated by confocal observation. These observations suggested that the bacteria isolated from rice soil could successfully recolonize internal tissues to protect the rice plant from infection. Because strains S170 and S9 were isolated from nonrhizospheric rice soil, it is necessary to determine their ability to colonize rice roots and the effect they have on the microbial community of nonrhizospheric rice soil. The microbial-culture method and high-throughput sequencing should now be implemented to study the culturable and uncultured microorganism diversity of nonrhizospheric rice soil treated by strains S170 and S9.

In conclusion, two Bacillus strains isolated from nonrhizospheric rice soil were studied to analyze their capacity to recolonize internal rice stem tissues and effectively suppress the growth of Fusarium, Botrytis cinerea, Colletotrichum gloeospoioides, Alternaria alternate, and Phytophthora parasitica among others. Both strains are biocontrol agents of M. oryzae in rice.

\section{Acknowledgments}

This work was supported by the Guide Foundation Project 
of Ningxia Academy of Agriculture and Forestry Sciences (NKYJ-16-26), the Innovation and Demonstration Project in the Whole Industry Chain of Ningxia Academy of Agriculture and Forestry Sciences (NKYZ-16-0906), the National Key Research and Development Project (2017YFD0201606), and the Key Research and Development Project of Ningxia (2018BBF02018-05).

\section{References}

Abraham, A., Narayanan, S. P., Philip, S., Nair, D. G., Chandrasekharan, A. and Kochupurackal, J. 2013. In silico characterization of a novel $\beta$-1,3-glucanase gene from Bacillus amyloliquefaciens: a bacterial endophyte of Hevea brasiliensis antagonistic to Phytophthora meadii. J. Mol. Model. 19:9991007.

Ahmad, Z., Wu, J., Chen, L. and Dong, W. 2017. Isolated Bacillus subtilis strain 330-2 and its antagonistic genes identified by the removing PCR. Sci. Rep. 7:1777.

Amruta, N., Prasanna Kumar, M. K., Narayanaswamy, S., Gowda, M., Channakeshava, B. C., Vishwanath, K., Puneeth, M. E. and Ranjitha, H. P. 2016. Isolation and identification of rice blast disease-suppressing antagonistic bacterial strains from the rhizosphere of rice. J. Pure Appl. Microbiol. 10:10431054.

Arrebola, E., Sivakumar, D. and Korsten, L. 2010. Effect of volatile compounds produced by Bacillus strains on postharvest decay in citrus. Biol. Control 53:122-128.

Chaiharn, M., Chunhaleuchanon, S. and Lumyong, S. 2009. Screening siderophore producing bacteria as potential biological control agent for fungal rice pathogens in Thailand. World J. Microbiol. Biotechnol. 25:1919-1928.

Chen, X., Zhang, Y., Fu, X., Li, Y. and Wang, Q. 2016. Isolation and characterization of Bacillus amyloliquefaciens PG12 for the biological control of apple ring rot. Postharvest Biol. Technol. 115:113-121.

Chun, J. and Bae, K. S. 2000. Phylogenetic analysis of Bacillus subtilis and related taxa based on partial gyrA gene sequences. Antonie van Leeuwenhoek 78:123-127.

Dagdas, Y. F., Yoshino, K., Dagdas, G., Ryder, L. S., Bielska, E., Steinberg, G. and Talbot, N. J. 2012. Septin-mediated plant cell invasion by the rice blast fungus, Magnaporthe oryzae. Science 336:1590-1595.

Food and Agriculture Organization of the United Nations. 2012. The state of food insecurity in the world 2012: economic growth is necessary but not sufficient to accelerate reduction of hunger and malnutrition. Food and Agriculture Organization of the United Nations, Rome, Italy. $62 \mathrm{pp}$.

He, Y., Zhu, M., Huang, J., Hsiang, T. and Zheng, L. 2019. Biocontrol potential of a Bacillus subtilis strain BJ-1 against the rice blast fungus Magnaporthe oryzae. Can. J. Plant Pathol. 41:47-59.

Huang, B., Lv, C., Zhuang, P., Zhang, H. and Fan, L. 2011. Endo- phytic colonisation of Bacillus subtilis in the roots of Robinia pseudoacacia. L. Plant Biol. 13:925-931.

Huang, W., Liu, X., Zhou, X., Wang, X., Liu, X. and Liu, H. 2020. Calcium signaling is suppressed in Magnaporthe oryzae conidia by Bacillus cereus HS24. Phytopathology 110:309-316.

Jambhulkar, P. P., Sharma, P., Manokaran, R., Lakshman, D. K., Rokadia, P. and Jambhulkar, N. 2018. Assessing synergism of combined applications of Trichoderma harzianum and Pseudomonas fluorescens to control blast and bacterial leaf blight of rice. Eur. J. Plant Pathol. 152:747-757.

Ji, S. H., Gururani, M. A. and Chun, S.-C. 2014. Expression analysis of rice pathogenesis-related proteins involved in stress response and endophytic colonization properties of $g f p$ tagged Bacillus subtilis CB-R05. Appl. Biochem. Biotechnol. 174:231-241.

Kim, J., Rohlf, F. J. and Sokal, R. R. 1993. The accuracy of phylogenetic estimation using the neighbor-joining method. Evolution 47:471-486.

Kim, P. I ., Ryu, J., Kim, Y. H. and Chi, Y.-T. 2010. Production of biosurfactant lipopeptides Iturin A, fengycin and surfactin A from Bacillus subtilis CMB32 for control of Colletotrichum gloeosporioides. J. Microbiol. Biotechnol. 20:138-145.

Kong, X., Han, B., Li, H., Liang, Y., Shao, K. and Liu, W. 2012. New biodegradable small-diameter artificial vascular prosthesis: a feasibility study. J. Biomed. Mater. Res. A 100:14941504.

Kumar, M. K. P., Amruta, N., Manjula, C. P., Puneeth, M. E. and Teli, K. 2017. Characterisation, screening and selection of Bacillus subtilis isolates for its biocontrol efficiency against major rice diseases. Biocontrol Sci. Technol. 27:581-599.

La Torre, A., Mandalà, C., Pezza, L., Caradonia, F. and Battaglia, V. 2014. Evaluation of essential plant oils for the control of Plasmopara viticola. J. Essent. Oil Res. 26:282-291.

Leelasuphakul, W., Sivanunsakul, P. and Phongpaichit, S. 2006. Purification, characterization and synergistic activity of $\beta-1,3-$ glucanase and antibiotic extract from an antagonistic Bacillus subtilis NSRS 89-24 against rice blast and sheath blight. Enzyme Microb. Technol. 38:990-997.

Li, R. Y., Wu, X. M., Yin, X. H., Liang, J. N. and Li, M. 2014. The natural product citral can cause significant damage to the hyphal cell walls of Magnaporthe grisea. Molecules 19:10279-10290.

Liu, X., Zhao, H. and Chen, S. 2006. Colonization of maize and rice plants by strain Bacillus megaterium C4. Curr. Microbiol. 52:186-190.

Li, W., Zhu, Z., Chern, M., Yin, J., Yang, C., Ran, L., Cheng, M., He, M., Wang, K., Wang, J., Zhou, X., Zhu, X., Chen, Z., Wang, J., Zhao, W., Ma, B., Qin, P., Chen, W., Wang, Y., Liu, J., Wang, W., Wu, X., Li, P., Wang, J., Zhu, L., Li, S. and Chen, X. 2017. A natural allele of a transcription factor in rice confers broad-spectrum blast resistance. Cell 170:114-126.

Liu, Y., Lai, Q., Dong, C., Sun, F., Wang, L., Li, G. and Shao, Z. 2013. Phylogenetic diversity of the Bacillus pumilus group 
and the marine ecotype revealed by multilocus sequence analysis. PLOS ONE 8:e80097.

Muthayya, S., Sugimoto, J. D., Montgomery, S. and Maberly, G. F. 2014. An overview of global rice production, supply, trade, and consumption. Ann. N. Y. Acad. Sci. 1324:7-14.

Nagpure, A., Choudhary, B. and Gupta, R. K. 2014. Chitinases: in agriculture and human healthcare. Crit. Rev. Biotechnol. 34:215-232.

Qi, Z., Yu, J., Shen L., Yu, Z., Yu, M., Du, Y, Zhang, R., Song, T., Yin, X., Zhou,Y., Li, H., Wei, Q. and Liu, Y. 2017. Enhanced resistance to rice blast and sheath blight in rice (Oryza sativa L.) by expressing the oxalate decarboxylase protein Bacisubin from Bacillus subtilis. Plant Sci. 265:51-60.

Rais, A., Shakeel, M., Hafeez, F. Y. and Hassan, M. N. 2016. Plant growth promoting rhizobacteria suppress blast disease caused by Pyricularia oryzae and increase grain yield of rice. BioControl 61:769-780.

Rais, A., Shakeel, M., Malik, K., Hafeez, F. Y., Yasmin, H., Mumtaz, S. and Hassan, M. N. 2018. Antagonistic Bacillus spp. reduce blast incidence on rice and increase grain yield under field conditions. Microbiol. Res. 208:54-62.

Schwyn, B. and Neilands, J. B. 1987. Universal chemical assay for the detection and determination of siderophores. Anal. Biochem. 160:47-56.

Shaldon, S. 1956. Estimation of serum-amylase: a simplified method. Lancet 268:547.

Sha, Y., Wang, Q. and Li, Y. 2016a. Screening and prevention of Bacillus biocontrol against rice blast. Chin. J. Biol. Control 32:474-484 (in Chinese).

Sha, Y., Wang, Q. and Li, Y. 2016b. Suppression of Magnaporthe oryzae and interaction between Bacillus subtilis and rice plants in the control of rice blast. SpringerPlus 5:1238.

Sha, Y., Zeng, Q., Wang, X., Shen, R., Liu, H. and Wang, X. 2018. Screening and control efficiency evaluation of Bacillus against rice blast Magnaporthe oryzae. Chin. J. Biol. Control 34:414-422 (in Chinese).

Shakeel, M., Rais, A., Hassan, M. N. and Hafeez, F. Y. 2015. Root associated Bacillus sp. improves growth, yield and zinc translocation for basmati rice (Oryza sativa) varieties. Front. Microbiol. 6:1286.

Thompson, J. D., Gibson, T. J., Plewniak, F., Jeanmougin, F. and Higgins, D. G. 1997. The CLUSTAL_X windows interface: flexible strategies for multiple sequence alignment aided by quality analysis tools. Nucleic Acids Res. 25:4876-4882.

Wiraswati, S. M., Rusmana, I., Nawangsih, A. A. and Wahyudi, A. T. 2019. Antifungal activities of bacteria producing bioactive compounds isolated from rice phyllosphere against Pyricularia oryzae. J. Plant Protect. Res. 59:86-94.

Wu, L., Xiao, W., Chen, G., Song, D., Khaskheli, M. A., Li, P., Zhang, S. and Feng, G. 2018. Identification of Pseudomonas mosselii BS011 gene clusters required for suppression of Rice Blast Fungus Magnaporthe oryzae. J. Biotechnol. 282:1-9.

Zhang, C., Zhang, X. and Shen, S. 2014. Proteome analysis for antifungal effects of Bacillus subtilis KB-1122 on Magnaporthe grisea P131. World J. Microbiol. Biotechnol. 30:17631774.

Zhang, L. and Sun, C. 2018. Fengycins, cyclic lipopeptides from marine Bacillus subtilis strains, kill the plant-pathogenic fungus Magnaporthe grisea by inducing reactive oxygen species production and chromatin condensation. Appl. Environ. Microbiol. 84:e0445-18. 